\title{
Analysis of Solar and Wind-Based Hybrid Power Plant Using HOMER Software (Case Study: EMAS BAYU Hybrid Power Plant in Bondan, Cilacap)
}

\author{
Supriyono $^{1 *}$, Devi Taufiq Nurrohman ${ }^{1}$, Agus Santoso $^{2}$, Betti Widianingsih $^{1}$ \\ ${ }^{1}$ Department of Electronics Engineering, State Polytechnic of Cilacap, Cilacap, Indonesia \\ ${ }^{2}$ Department of Mechanical Engineering, State Polytechnic of Cilacap, Cilacap, Indonesia \\ Corresponding author's email: rzx.clcp@gmail.com
}

\begin{abstract}
Solar energy is an energy source that is widely used because it is free energy, eco-friendly and very abundant, especially in tropical countries. However, the energy obtained from solar energy is inconsistent and is heavily influenced by environmental factors. Recently, many researchers have developed hybrid power plants which combine two or more different energy sources in the same system. In this research, we develop a hybrid power plant with an off-grid system (not connected to the national electricity company) that utilizes solar and wind energy. The hybrid power plant being developed is installed in Bondan hamlet, Kampung Laut District, Cilacap Regency. The installed power plant is determined for its performance by analyzing several parameters such as total energy production, net present cost (NPC) and cost of energy (COE). These parameters are analyzed using software which called hybrid optimization of multiple energy resources (HOMER). The simulation results show that the total energy generated from photovoltaics (PV) is 5.8 times higher than that of the wind turbine, with details being 10,480 kWh/year from PV and 1,805 kWh/year from the wind turbine. For the COE and NPC values are Rp. 14,266/kWh and Rp. 1,190,000,000, respectively.
\end{abstract}

Keywords: Hybrid Power Plant, Solar Energy, Wind Energy, HOMER.

\section{INTRODUCTION}

Energy, especially electrical energy, is a very important sector and supports the sustainability of development activities in a country or region. Based on the source, there are two sources of energy, namely nonrenewable energy sources and renewable energy sources [1]. Non-renewable energy sources are abundant and produce more electrical energy at lower cost[2]. However, it produces pollution, especially carbon emissions that are harmful to the environment and human health[3]. Recently, renewable energy sources such as solar, wind, biomass and micro-hydro have been utilized because energy sources are very abundant, unlimited and eco-friendly[4]. In addition, this energy source has potential to be applied in remote areas that cannot be reached by the national electricity company[5]. However, energy produced by renewable energy sources is usually unstable, highly dependent in location and influenced by weather conditions[6]. Therefore, to overcome the shortage, hybrid power plants which use more than one energy source are developed[7].

Bondan Hamlet, Ujung Alang Village is one of the areas in Kampung Laut sub-district, Cilacap district which cannot be reached by the national electricity company. This region is in the position of $7^{\circ} 40^{\prime} \mathrm{N}$ (latitude) and $108^{\circ} 52^{\prime} \mathrm{E}$ (longitude). In 2017, a hybrid power plant was built using PV arrays and wind turbines. The total power generation capacity is $13.16 \mathrm{kWp}$ which is composed of $8.16 \mathrm{kWp}$ from the PV array and 5.00 $\mathrm{kWp}$ from the wind turbine. Recently, out of 80 houses, only 40 have been supplied with electricity from this power plant. In 2019 this power plant was inaugurated, and it is called the EMAS BAYU hybrid power plant.

Hybrid power plants are usually built at a higher cost for the purchase of components and analysis of the performance and reliability of a hybrid system is very complex [8]. Software is usually used for design, analysis, simulation, economics, and optimization planning. There are many widely used software, including HOMER, 
RETScreen, Pvsyst, and iHOGA. Among these software, HOMER is the one that is widely used because it is free software, easy to understand, and has a very short computation time[9]. In addition, HOMER can be used for evaluation of a single network design (off-grid) and a network connected to the system (grid-connected or ongrid)[10].

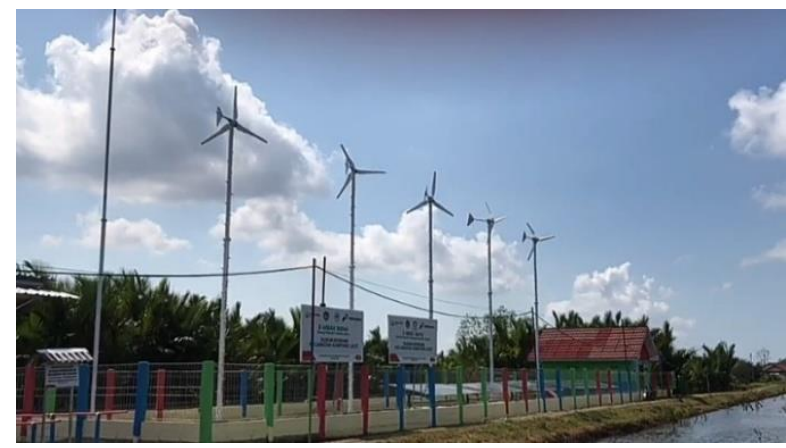

Figure 1. EMAS BAYU Hybrid Power Plant in Bondan hamlet, Cilacap, Indonesia

EMAS BAYU hybrid power plant is a power plant with off-grid system (not connected to the system or electricity network). This research analyzes the performance and reliability of the power plant using HOMER software. The analyzed parameters include total energy production, NPC and COE. The costs for capital, maintenance and operations are stated in rupiah ( $\mathrm{Rp})$. The results of the analysis in this study can be used as supporting data in management activities and expansion of power plants to supply houses that are not yet powered.

\section{METHOD}

To determine the value of total energy production, NPC and COE using the HOMER software, briefly, there are three main stages carried out, namely the technical data collection stage, the economic data collection stage, and the simulation and analysis stage. The technical data collection stage includes collecting data on the potential for solar energy, wind energy, and data on electrical loads used by power plant customers. Solar and wind energy potential data is obtained by entering coordinates in the HOMER software. Meanwhile, electric load data is obtained from direct data collection at the research location. The next stage is the collection of economic data which is done by looking for data related to initial capital costs, replacement costs and operational and maintenance $(\mathrm{O} \& \mathrm{M})$ costs. Initial capital costs represent real costs for the construction of a power plant. Meanwhile, the replacement and $\mathrm{O} \& \mathrm{M}$ costs in this study are assumed to be 10 years. After the data is obtained, a HOMER simulation is carried out using the data that has been collected and based on the model of the EMAS BAYU hybrid power plant that has been built in the research location. The flow chart of this study is shown in Figure 2.

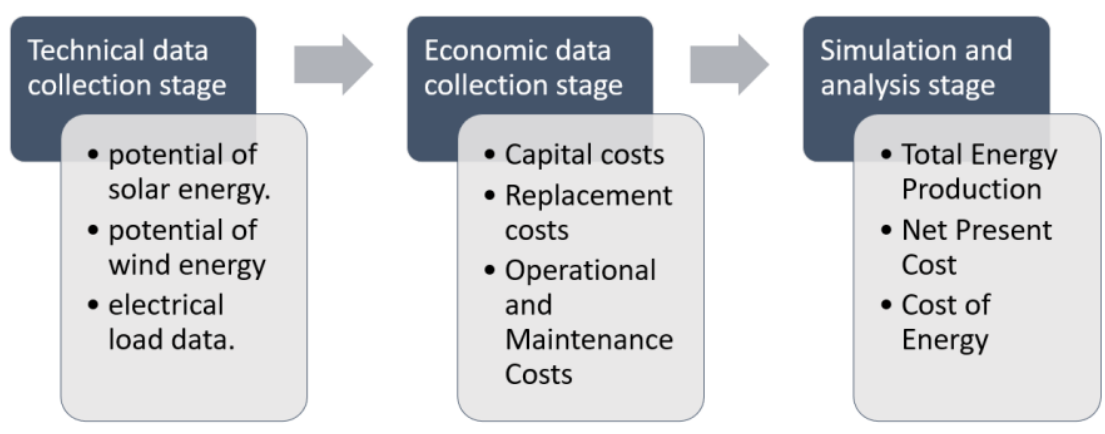

Figure 2. Flow chart for determining total energy production, NPC and COE using HOMER software

\section{RESULT AND DISCUSSION}

\subsection{Potential of Solar and Wind Energy}

The potential for solar and wind energy in Bondan Hamlet that will be used for simulations is taken from NASA's surface meteorological energy and solar energy. During one year, data on the potential for solar energy which includes the clarity index and daily radiation in Bondan Hamlet is shown in Figure $3 \mathrm{a}$ and data on the potential for wind energy is shown in Figure $3 b$.
Data on the potential for solar energy can be determined based on clearness index and daily radiation data. The clearness index shows a measure of the level of clarity of the atmosphere. It has a range from 0 to 1 and is a dimensionless quantity. A high clarity index indicates sunny conditions while a low value indicates cloudy conditions[11]. Based on the clearness index data (black line) in Figure 3a, the highest clearness index was in June at 0.518 . For daily radiation, the highest radiation is found in September, which is $5.03 \mathrm{kWh} / \mathrm{m}^{2} /$ day. Wind energy potential is determined based on wind speed data. In a period of one year, the wind speed in Bondan hamlet is between $3.04 \mathrm{~m} / \mathrm{s}$ to $6.04 \mathrm{~m} / \mathrm{s}$. If the potential for solar 
energy and wind energy is determined based on the average, the average radiation daily and wind speed are $4.6 \mathrm{kWh} / \mathrm{m}^{2} /$ day and $4.42 \mathrm{~m} / \mathrm{s}$, respectively. By looking

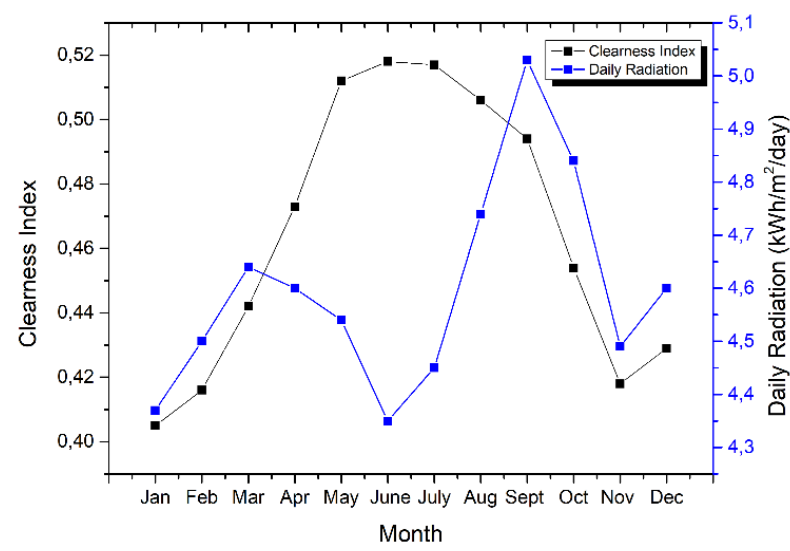

(a)

Figure 3. Potential of a). Solar energy, b). Wind energy

\subsection{Electrical Load Data}

EMAS BAYU hybrid power plant was built in the center of the Bondan hamlet. The electrical energy generated by PV and wind turbines is stored in advance in the battery and distributed to residents via two different routes, which are called the west route and the east route. Electricity load data is taken from the two lines for three different days for 24 hours from 00:00 to 23:00. The at data on solar and wind energy, Bondan hamlet is a suitable area to develop hybrid power plants based on solar and wind energy.

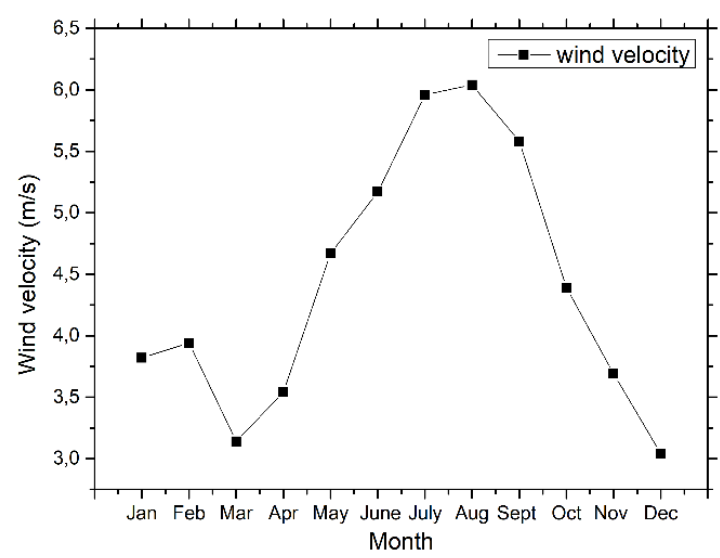

(b)

average electric load data for each line and the total load is shown in Figure 4. If we look at the graph on the west and east lines, the highest electrical energy load occurs at 6.00. It happens because most residents do household activities such as cooking. Electrical energy load began to rise again at 18.00 . This increase was mainly due to lighting in homes and in public facilities. Electrical energy load starts to rise again at 18.00. If the electric loads for the west and east lines are combined, the highest load for 24 hours is $1.6 \mathrm{~kW}$.
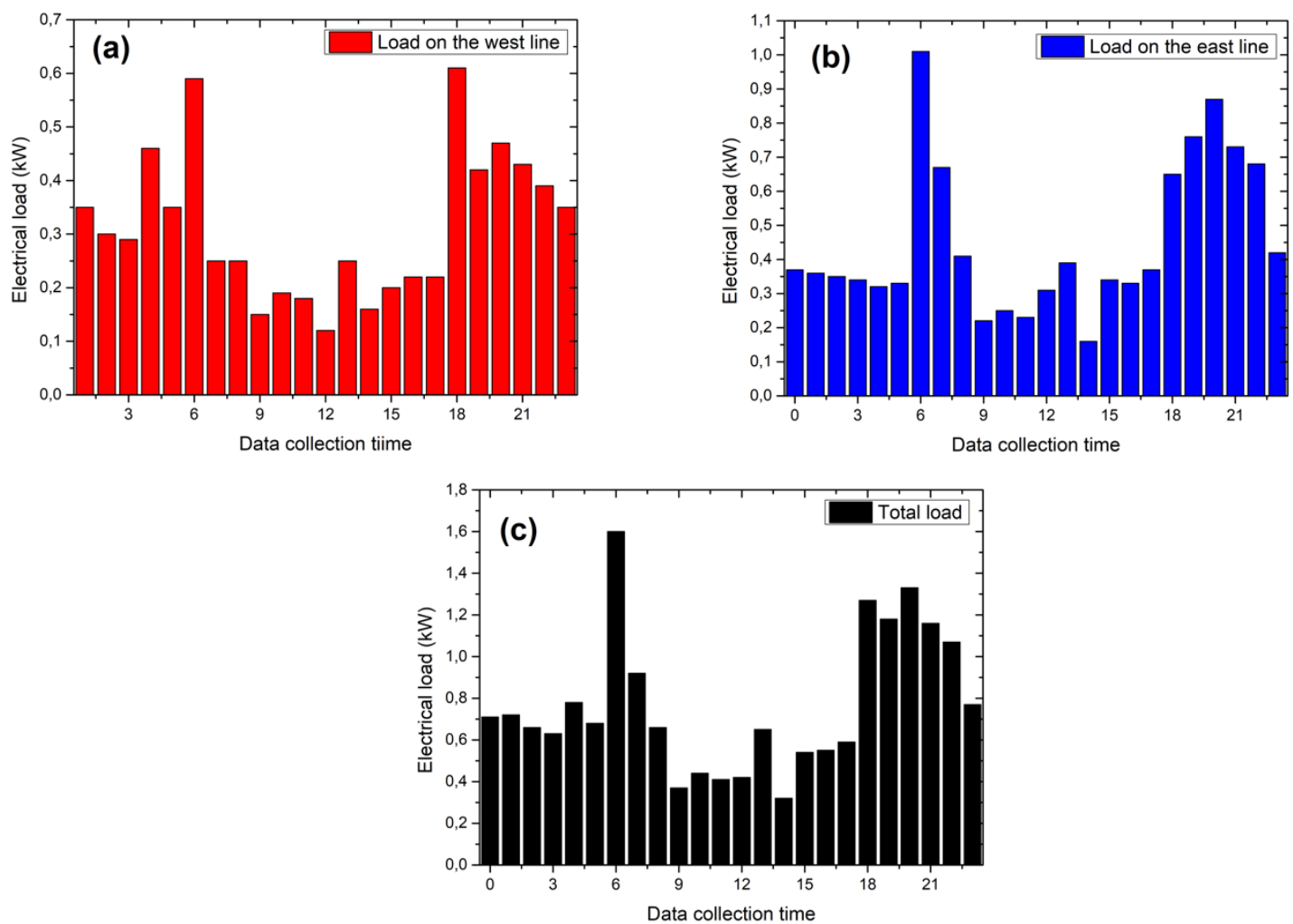

Figure 4. Daily profile of electrical load for (a). West line, (b). East line, and (c). Total load. 


\subsection{Setting of Power Plant Economic Parameters}

EMAS BAYU hybrid power plant is composed of 5 main components, namely PV array, wind turbine, MPPT, battery, and converter. The number of PV that have been installed to date is 24 units, which are composed of 12 units with a capacity of $330 \mathrm{Wp}$ and 12 units with a capacity of $350 \mathrm{Wp}$. The total PV capacity is $8.16 \mathrm{kWp}$. For wind turbines, up to now 5 wind turbines have been installed where the capacity of each wind turbine is $1 \mathrm{~kW}$, so the total capacity is $5 \mathrm{~kW}$. The capacities of the MPPT, battery and converter are 11.52 $\mathrm{kW}, 126.72$, and $12 \mathrm{~kW}$, respectively. The initial capital costs for these five components are shown in Table 1 . The lifetime for all components in a power plant is assumed to be the same, namely 10 years. During this period, replacement costs are assumed to be $50 \%$ of initial capital costs, while operational and maintenance costs are assumed to be $5 \%$ of initial capital costs. In summary, the capital costs, replacement costs, lifetime, and operational $\&$ maintenance costs are shown in Table 1.

Table 1. Capacity, capital cost, liftime, $\mathrm{O} \& \mathrm{M}$ cost for each component

\begin{tabular}{cccccc}
\hline Component & Capacity & Capital cost & $\begin{array}{c}\text { Replacement } \\
\text { cost }\end{array}$ & $\begin{array}{c}\text { Lifetime } \\
\text { (years) }\end{array}$ & O \& M cost \\
\hline Photovoltaics $(\mathrm{PV})$ & $8.16 \mathrm{~kW}$ & Rp. 96.000 .000 & Rp. 48.000 .000 & 10 & Rp. 4.800 .000 \\
Wind turbin & $5 \mathrm{~kW}$ & Rp. 175.000 .000 & Rp. 87.500 .000 & 10 & Rp. 8.750 .000 \\
MPPT & $11.52 \mathrm{~kW}$ & Rp. 40.000 .000 & Rp. 20.000 .000 & 10 & Rp. 2.000 .000 \\
Battery & $126.72 \mathrm{kWh}$ & Rp. 180.000 .000 & Rp. 90.000 .000 & 10 & Rp. 9.000 .000 \\
Converter & $12 \mathrm{~kW}$ & Rp. 120.000 .000 & Rp. 60.000 .000 & 10 & Rp. 6.000 .000 \\
\hline
\end{tabular}

\subsection{Simulation results using HOMER software}

After the technical data (potential solar energy, wind energy and load profile) and economic data (capital costs, replacement costs, operational and maintenance costs) have been collected, the next step is simulation and analysis using HOMER software. Figure 5 shows a schematic of a hybrid system in the HOMER software. The PV array with the converter, battery and wind turbine is connected to the primary load (DC terminal) and the converter is connected between the DC and AC bus bars. Then the output of the converter is connected to a load called the west line load and the east line load.

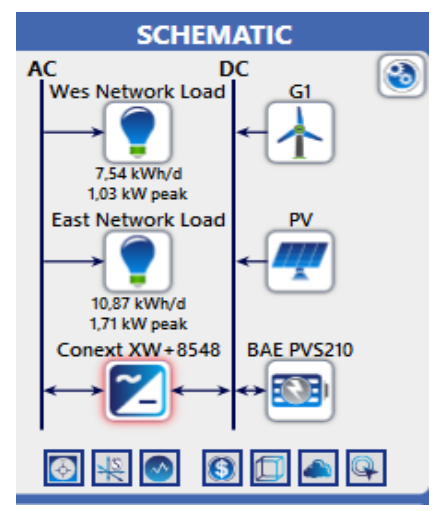

Figure 5. Hybrid system schematic in HOMER software

Table 2 shows the simulation results. The total energy production for one year is $12,285 \mathrm{kWh}$. The energy produced is dominated by the energy obtained from PV, which is $10,480 \mathrm{kWh}$, while the energy produced by wind energy is $1,805 \mathrm{kWh}$. The energy produced by $\mathrm{PV}$ is almost 5.8 times the energy produced by wind energy. Furthermore, the net present cost (NPC) data is Rp. 1,280,000,000 and the cost of energy (COE) is Rp. $14,266 / \mathrm{kWh}$. The COE value obtained from the simulation results shows that the price is higher than the price currently on the market, especially in Indonesia. Therefore, further investigations are needed to determine the performance of power plants at different renewable energy sources. The simulation results also show that the electricity generated by PV is greater, therefore, it is very interesting to investigate the performance of PV-based power plants by increasing the capacity of the battery to supply electrical energy needs at night.

Table 2. Data obtained from the simulation results using HOMER software

\begin{tabular}{cc}
\hline Parameter & The data obtained \\
\hline Total of energy production & \\
Production of PV energy/ & $12.285 \mathrm{kWh} /$ year \\
year & $10.480 \mathrm{kWh} /$ year \\
Production of wind & $1.805 \mathrm{kWh} /$ year \\
energy/year & Rp. 1.280 .000 .000 \\
Net present cost & Rp. $14.266 / \mathrm{kWh}$ \\
Cost of energy & \\
\hline
\end{tabular}

\section{CONCLUSION}

The performance and reliability of the EMAS BAYU hybrid power plant have been successfully investigated using the HOMER software. Performance and reliability are determined based on the NPC and COE values, which are related to technical data including the potential for solar energy, wind energy, and electricity loads and economic data including initial capital costs, replacement costs, operational and maintenance costs. The results 
obtained indicate that the energy produced during the year is dominated by energy from PV, which is 10,480 $\mathrm{kWh}$. In addition, the NPC and COE values from the simulation results are Rp. 1,280,000,000 and Rp. $14,266 / \mathrm{kWh}$.

\section{ACKNOWLEDGMENT}

The reported work was financially supported by Program Penelitian Dosen Pemula, State Polytechnic of Cilacap (contract number: 22/PL.43/PT.01.03/2020). The author would like to thank the financial support provided in the research and completion of this article.

\section{REFERENCES}

[1] A. A. Setiawan, B. M. Sopha, M. T. Sistem, F. Teknik, and U. G. Mada, "Hybrid Power System Modeling for Electricity System in Sumbawa District ( Hybrid Power System Modeling )," vol. 3, no. 1, pp. 28-36, 2015.

[2] A. A. M. Ahmed, Sawsan Ahmed Elhouri Osman, "Renewable Energy Advantages and Disadvantages," Int. J. Res. Sci. Manag., vol. 3, no. 10, pp. 7-9, 2016.

[3] O. B. Awodumi and A. O. Adewuyi, "The role of non-renewable energy consumption in economic growth and carbon emission: Evidence from oil producing economies in Africa," Energy Strateg. Rev., vol. 27, p. 100434, 2020, doi: 10.1016/j.esr.2019.100434.

[4] M. Shervinzakeri and M. M. Taghizadeh, "Review on Renewable Energy, Sustainable Energy and Clean Energies," Tech. J. Eng. Appl. Sci., no. August, pp. 120-123, 2014.
[5] Mustaqimah, "Optimization of Renewable Energy Hybrid System for Grid Connected Application," Rona Tek. Pertan., vol. 5, no. 2, pp. 379-382, 2012.

[6] I. Baba Kyari and J. Ya'u Muhammad, "Hybrid Renewable Energy Systems for Electrification: A Review," Sci. J. Circuits, Syst. Signal Process., vol. 8, no. 2, p. 32, 2019, doi: 10.11648/j.cssp.20190802.11.

[7] R. T. A. Al-Rubaye, A. T. A. Al-Rubaye, and M. M. Al-Khuzaie, "Optimal Design of Hybrid Renewable Energy System off grid in AlDiwaniyah, Iraq," IOP Conf. Ser. Mater. Sci. Eng., vol. 454, no. 1, 2018, doi: 10.1088/1757899X/454/1/012103.

[8] B. Ceran and R. Szczerbowski, "Energy cost analysis by hybrid power generation system," IOP Conf. Ser. Earth Environ. Sci., vol. 214, no. 1, 2019, doi: 10.1088/1755-1315/214/1/012001.

[9] P. Kumar and S. Deokar, "Designing and Simulation Tools of Renewable Energy Systems: Review Literature," Adv. Intell. Syst. Comput., vol. 563, no. May, pp. 315-324, 2018, doi: 10.1007/978-981-10-6872-0_29.

[10] U. Wibawa and M. Shidiq, "Hybrid Power Plant Feasibility Study in Mandangin," J. Environ. Eng. Sustain. Technol., vol. 03, no. 02, pp. 8591, 2016.

[11] C. S. Lai, X. Li, L. L. Lai, and M. D. McCulloch, "Daily clearness index profiles and weather conditions studies for photovoltaic systems," Energy Procedia, vol. 142, pp. 77-82, 2017, doi: 10.1016/j.egypro.2017.12.013. 